\title{
Legitimate division of large data sets, salami slicing and dual publication, where does a fraud begin?
}

\author{
Jon Karlsson • Philippe Beaufils
}

Published online: 24 January 2013

(c) Springer-Verlag Berlin Heidelberg 2013

The number of submitted manuscripts is increasing sharply from year to year in almost all international journals. Among the many reasons for the increased number of manuscripts, salami slicing deserves special attention. Salami slicing consists of splitting data from the same research into small units, each of which is submitted-and in many cases published-separately. Whereas a single study previously led to the submission of a single-large — article, the data may now be divided into several manuscripts, which are subsequently submitted to a single journal or to several journals. The prevalence of salami slicing, although not unappreciable, is difficult to determine. Reported values have ranged from only $1 \%$ [1] or $1.8 \%$ [6] to more than $15 \%$ [2]. Salami slicing is driven by an author's desire or need to achieve a larger number of publications, in order to gain recognition, move up on the academic career ladder, attract research funds by increasing the institution's visibility and/or obtain financial gain [3, 7, 9].

Dividing a research project into several papers is not always incorrect or should not be criticised, as some topics are too large for a single publication. A study of partial anterior cruciate ligament tears, for instance, needs to be reported in several papers, if only, to clarify the objectives (epidemiology, laxity, MRI ...). Moreover, a journal may ask experts to write about their field of knowledge, in

\footnotetext{
J. Karlsson ( ()

Department of Orthopaedics, Sahlgrenska University Hospital, SE-431 80 Mölndal, Sweden

e-mail: Jon.karlsson@telia.com

P. Beaufils

Orthopaedics and Traumatology Department, Versailles

Hospital, 78150 Le Chesnay, France

e-mail: pbeaufils@ch-versailles.fr
}

which case the experts use data from their own previously published studies, which are cited in the new paper.

At the other end of the spectrum, dual publication is a completely different phenomenon. In dual publication, the authors knowingly submit two manuscripts reporting identical data to two different journals, either simultaneously or successively. This behaviour, designated dual publication or self-plagiarism by ethics committees (International Committee of Medical Journal Editors, ICMJE [1]; and the Committee on Publication Ethics, COPE [4]), clearly constitutes fraud, since the publication of a manuscript in a journal implies copyright transfer to that particular journal. However, the publication of the article in a different language can take place, provided the original article is cited and permission is obtained from the journal that published it. The detection of dual publication invariably leads to a serious sanction, namely the formal retraction of the article. A 2012 study [5] identified 742 retracted publications in the biomedical literature over the last 10 years, with an increased number in recent years. Dual publication is clearly the most common reason for retraction. Retraction involves the notification of international databases and journal publishers to explain the decision and its reasons. Banning decisions may be taken against the authors by the editorial board(s) of the journal(s) in which the articles were published or even by the publishers. In addition, if applicable, a notice may be sent to the administration of the university with which the authors are affiliated. This usually leads to serious negative consequences for the author in question and could even be described as 'career suicide'.

In real life, the limits between the appropriate division of a manuscript into smaller pieces worthy of publication as separate papers and dual publication are hazy: no situations are all black or all white [8, 9]. Instead, a continuum exists between the appropriate division of the data and dual 
publication, with salami slicing located somewhere in the middle. Editors are increasingly encountering these intermediate cases of self-plagiarism. Salami slicing can take place in various ways, such as the successive submission to the same journal or to different journals of manuscripts on the same topic based on research conducted, but using the same patient cohort. If the original publication is cited in the manuscript, transparency is ensured and the editor can then determine whether the new information supplied by the manuscript is worthy of publication.

In contrast, simultaneously submitting two manuscripts that report exactly the same study conducted on the same cohort but in different formats (e.g. original article and technical note), without informing the journals of the dual submission, indicates a deliberate attempt on the part of the authors to conceal their behaviour. In such cases, the editors are unable to detect the dual submission, and if both manuscripts are accepted, they are published at the same time. A recent manuscript published simultaneously in Orthopaedics and Traumatology: Surgery and Research (OTSR) and Knee Surgery Sports Traumatology and Arthroscopy (KSSTA) prompted this common editorial. Deliberate fraud? Ethical mistake? The distinction is a matter of interpretation.

In any case, dual publication must be combatted vigorously. Sanctions available to editors include the retraction of the article, a decision to ban the authors temporarily from publishing their work in the journals, a notice sent to editors and publishers of other journals and a letter of censure sent to the authors. Each editorial board must choose from these tools after obtaining advice from its ethical committee.
As editors, we work very hard to ensure that our readers can trust the science reported in the articles we publish. The manuscripts are selected through a painstaking process of peer review. In addition, a code of publication ethics must be accepted by the entire orthopaedic community. In the long term, educational efforts must target all those involved, including the authors, universities, editorial boards and publishers.

\section{References}

1. Babalola O, Grant-Kels JM, Parish LC (2012) Ethical dilemmas in journal publication. Clin Dermatol 30(2):231-236

2. Committee on Publication Ethics Guidelines (2012) http:// publicationethics.org/resources/guidelines

3. Durani P (2006) Duplicate publications: redundancy in plastic surgery literature. J Plast Reconstr Aesthet Surg 59(9):975-977

4. Hennessey KK, Williams AR, Afshar K, Macneily AE (2012) Duplicate publications: a sample of redundancy in the Journal of Urology. Can Urol Assoc J 6(3):177-180

5. International Committee of Medical Journal Editors (2012) Uniform requirements for manuscript submitted to biomedical journals. http://www.icmje.org/

6. Neill US (2008) Publish or perish, but at what cost? J Clin Invest 118(7):2368

7. Samp JC, Schumock GT, Pickard AS (2012) Retracted publications in the drug literature. Pharmacotherapy 32:586-595

8. Schein M, Paladugu R (2001) Redundant surgical publications: tip of the iceberg? Surgery 129(6):655-661

9. Spielmans GI, Biehn TL, Sawrey DL (2010) A case study of salami slicing: pooled analyses of duloxetine for depression. Psychother Psychosom 79(2):97-106 